\title{
Spectrum Trading in India and 5G
}

\author{
Purnendu S. M. Tripathi and Ramjee Prasad \\ Center for TeleInFrastruktur (CTiF), Aalborg University, Denmark; \\ email:\{in_psmt,Prasad\}@es.aau.dk
}

Received July 2013; Accepted August 2013

\begin{abstract}
Currently radio spectrum is largely managed through Command and Control method. Public mobile services require spectrum below $3 \mathrm{GHz}$ for providing cost effective services. The existing method has created artificial shortage of spectrum especially below $3 \mathrm{GHz}$. Spectrum trading is a new concept in which service providers are permitted to purchase spectrum from the market to fulfil their requirements. Spectrum trading has not yet been permitted in India. This paper provides an overview of possibilities of spectrum trading in India and concludes that necessary ingredients are present in India for spectrum trading and it could provide a boost to the Indian telecom sector. Further, it will also discuss spectrum issue related with $5 \mathrm{G}$ in the direction of millimeter waves.
\end{abstract}

Keywords: Radio spectrum, 2G/3G services, spectrum trading, NFAP 2011.

\section{Introduction}

The journey of mobile communications started in the early 1980s with first generation $(1 \mathrm{G})$ mobile communications with analog technology primarily for voice only. Now we are in fourth generation mobile communications with all IP based packet switched network, seamless mobility and high data rate with 1 Gbps peak data rate for downlink (DL) and 500 Mbps for uplink (UL) [1]. The spectrum requirements upto $4^{\text {th }}$ generation mobile communications can easily be met upto $6 \mathrm{GHz}$. Although, the bands for IMT services have been

Journal of ICT Standardization, Vol. 1, 159-174.

doi:10.13052/jicts2245-800X.12a3

(C) 2013 River Publishers. All rights reserved. 
identified by the ITU but these bands are not free. It has already been assigned long back for other usage. The current spectrum management process does not allow spectrum holders the flexibility to respond quickly to changes in the market demand and technology, resulting spectrum lying underutilised, which creates artificial scarcity [2].

The $2 \mathrm{G}$ in $900 / 1800 \mathrm{MHz}$ band and $3 \mathrm{G}$ mobile services in $2.1 \mathrm{GHz}$ band are running successfully in India [3]. 4G services in 2.3-2.4 GHz band has also entered into Indian market but has not yet rolled out satisfactorily due to limited coverage. In the USA and European countries, $4 \mathrm{G}$ services are running successfully in lower bands by allowing use any technology in any band[1]. The assigned spectrum is contiguous, in case of shortage, operators can get additional spectrum from the market through spectrum trading. However, the situation in India is just reversed, here assigned spectrum is un-liberalized (except acquired through auction) and highly fragmented. Therefore, a flexible environment is required to be created for further expansion of telecom sector so that $4 \mathrm{G}$ services can be reached at every corner of India.

Spectrum trading [4] is an option through which flexibility can be increased and spectrum,assigned to a particular service, can be easily transferred for other usage. Spectrum trading improves the efficiency and facilitates new services to enter in the market. Spectrum trading has already been implemented in most of the countries but it has not yet been introduced in India. Presently, spectrum has been delinked with license and available through market mechanism only. At this stage, Indian market seems to be mature enough for spectrum trading.

The paper is organized as follows: Section 2 defines the current spectrum management practice and spectrum trading. Section 3 describes the present status of telecom sector of India and Section 4 describes possible regulation need to be formulated for adoption of spectrum trading in India. Section 5 describes about the spectrum requirement for $5 \mathrm{G}$ services and Section 6 concludes the paper.

\section{Spectrum Trading}

The traditional method used for allocation of spectrum is known as 'Command and Control' method [4] as shown in Figure 1. In this method, radio spectrum is divided into different spectrum bands that are allocated to specific radio communications services, such as mobile, fixed, broadcast, fixed satellite and mobile satellite services on an exclusive basis. This command-and-controlbased spectrum management framework guarantees that the radio frequency 
Spectrum Trading in India and $5 G \quad 161$

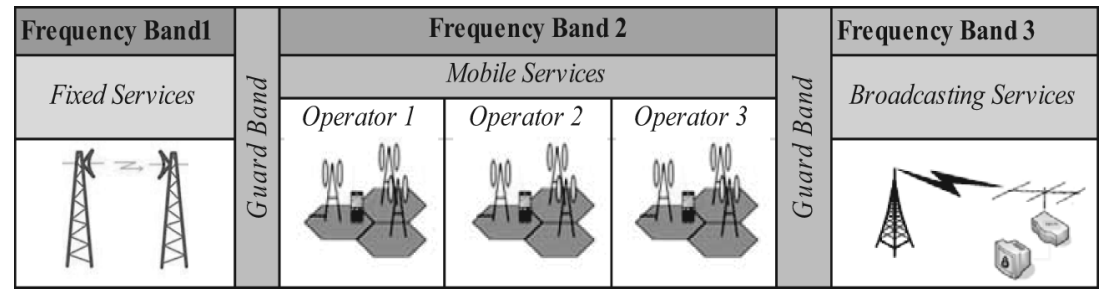

Figure 1 Command and control method of spectrum allocation.

spectrum will be exclusively licensed to an authorized user (i.e. Licensee) and can use the spectrum without any interference.

The command and control method is widely criticized for non-efficient use of spectrum but it has several advantages like providing interference free environment due to rigid technical conditions, provision of guard band between the two allocations and separate spectrum allocation for each service and users. It plays an effective role in the expansion of many services (like GSM) worldwide through co-ordination and harmonization.

The major flaw with the Command and control method is that it does not ensure efficient use of spectrum. Once the spectrum has been assigned to a user, spectrum utilization cannot be questioned during the licensing period provided he fulfill the terms and conditions of the license. Spectrum allocated to one radio communication service cannot be replaced by other services even knowing that spectrum is underutilized. For example, terrestrial TV services, where at least $8 \mathrm{MHz}$ of spectrum (Bandwidth of one channel) remains largely unused but the licensing condition does not permit broadcasters to use this unused spectrum for other services. Another example is mobile telecom services, where a block of spectrum assigned for the entire service area. While spectrum could be heavily used in urban areas, it would be underutilized in rural areas. The operator cannot share this spectrum with other operators under the existing regime.

The current spectrum management approach is under pressure as it does not lead to efficient spectrum use. However, it could be justified in some way that it successfully avoids interference and played an effective role in expansion of few services through co-ordination and harmonization. The emergence of new technologies and services, like cognitive radio, UWB, Broadband, Wi-Max, $4 \mathrm{G}$ etc., need for greater mobility, greater capability of market players and blurring the boundaries between different services and technologies has put a great pressure on radio frequency spectrum manager for efficient and economical use of spectrum. Regulators are adopting different means to improve 
the spectrum efficiency. Spectrum trading is one tool, through which spectrum efficiency can be improved by making slight modification in the regulatory provisions.

Spectrum trading is a market based mechanism where buyers and sellers determine the assignments of spectrum and its uses [5]. In spectrum trading, seller transfers the right of spectrum usage, in full or part, to buyer while retaining the ownership. Spectrum trading is considered as economically efficient because trade will only take place if the spectrum is worth more to the new user than former it was in the old user [2]. Trading is effective only when it is clubbed with liberalization. Combined have potential to remove the artificial scarcity of the spectrum as trading help to acquire spectrum more readily from the market and liberalization facilitates new technologies/ services to enter in the market. These factors provide consumers with greater choice. The unit of trading can be licensing parameters namely the bandwidth, the geographical area and the duration. This leads to the possibility of partial transfer usage right in terms of bandwidth, area or time. Trading is technically considered as part of a spectrum sharing. However, trading differs in terms of usage right, where the total usage right transferred to seller for a specified period whereas in sharing, seller gets temporary right of spectrum usage, exclusive rights rests with the seller [6].

Trading has first been implemented in New Zealand and Australia. Thereafter, USA, UK, El Salvador, Guatemala and many European countries have introduced spectrum trading in specific bands, which are in demand for commercial use. In Europe, Denmark was the first country, which allowed trading in 1997 followed by Switzerland in 1998. The salient features of spectrum trading in Denmark are given below [7]:

- Spectrum trading is allowed in all GSM bands, $2.1 \mathrm{GHz}, 3.5 \mathrm{GHz}$, $10.5 \mathrm{GHz}, 26-29 \mathrm{GHz}$ bands. Spectrum in these bands has been assigned through market mechanisms, auction or public tender

- Default duration for the granted usage is 15 years

- Usage rights can be traded partially for bandwidth and geographical area. No partial trade is allowed for time.

- Reference of usage right (frequency licence number) that will be transferred is required at notification of intent to trade

- Information about the license namely license number, frequency, geographical area etc. Needs to publish prior to the transaction

- Approval of transaction by the Authority is required for the trading part of the licence issued after an auction 
- Transaction is required to be made public, which contains information like, identity of parties, reference of original authorization and new authorization, date at which transfer becomes effective, geographic area, frequency band and expiration date.

- Trade may be refused there is unpaid payment for a licence issued following an auction, licence holder cannot guarantee obligations on the provision of services with remaining spectrum.

Spectrum trading has been allowed long back in most countries but the market has not been successful in Australia, New Zealand and European countries because operators in these countries hold good amount of spectrum in each band, and lack of sufficient participation. The activity level is very high in the US where mobile operators have bought spectrum from each other as well as from broadcasters and other niche spectrum holders [8].

\section{Indian Telecom Sector}

The Indian telecom journey began in 1994, when telecom sector was opened for private sector. The first private sector wire-line and cellular licenses were issued in 1995. From then on, Indian telecom has seen several milestones crossed and many missteps that provided valuable lessons. The telecom industry has witnessed a phenomenal growth in the last decade with 898.02 million phone connections with overall teledensity of 73.32 at the end of March, 2013 (Figure 2), Today, India is the second largest and fastest growing telecom market in the world in terms of the number of wireless connections. The growth is predominately in the wireless sector, which contributes $96.64 \%$ (867.80 million) of total phone connections [9].

Telecom services are operating in $800 \mathrm{MHz}$ (CDMA), $900 \mathrm{MHz} / 1800$ $\mathrm{MHz}$ (GSM), 2.1 GHz (3G) and $2.3 \mathrm{GHz} / 2.5 \mathrm{GHz}$ (BWA) in India [3]. India is geographically $5^{\text {th }}$ biggest country with 3.23 million $\mathrm{Km}^{2}$. The country has been divided into 22 service areas for the purpose of telecom services. These service areas have further been divided into various categories viz. 'Metro', 'A','B' and 'C' based on the population, traffic pattern and revenue generations capacity. Service providers have been given a license for providing telecom services in these service areas. The Indian telecom scenario is bit unusual, if not unique, in terms of the number of operators and assigned spectrum. India is one of the few countries where CDMA and GSM both the technologies are in operation for mobile telecom services. Presently, 15 operators are providing different telecom services in India, out of which 


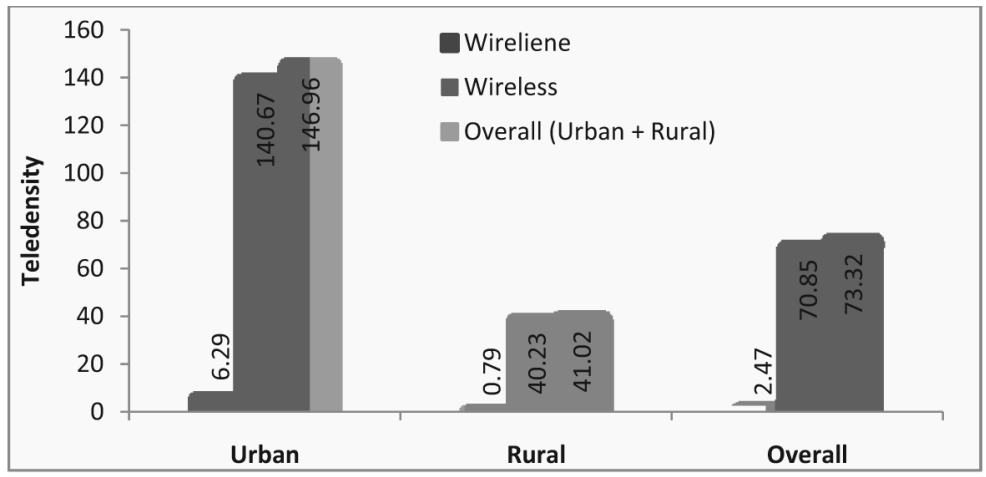

Figure 2 Teledensity in urban and rural india.

8 are providing in all TSAs ( 6 in GSM and 1 each in CDMA \& BWA). The average spectrum hold by each operator is between $10-15 \mathrm{MHz}$ across all bands (i.e. $800,900,1800,2100 \mathrm{MHz}$ paired bands), about one-fourth of the international average $[9,10]$. A total of $310 \mathrm{MHz}$ across the bands has been allocated for telecom services. There are no pan India presence in CDMA and 3G services except Public Sector Unit (PSU) Bharat Sanchar Nigam Limited (BSNL) /Mahanagar Telephone Nigam Limited (MTNL). BSNL is operating in all TSAs except Delhi and Mumbai, where MTNL is operating. Combinedly MTNL and BSNL present in all TSAs as one PSU. A detail of no. of operators, average spectrum holding etc. is given in Table 1 (BSNL/MTNL considered as an operator).

Initially spectrum assigned for $2 \mathrm{G}$ (GSM/CDMA) services to each operator was $4.4 \mathrm{MHz}$ (GSM) /2.5 MHz (CDMA) to start the service. Further, increment made (up to $10 \mathrm{MHz}$ ) in piecemeal subject to meeting of strict subscriber base criteria (devised for allocation of additional spectrum) [11]. Therefore, spectrum assigned to operators is so fragmented that in some cases, it is only $0.2 \mathrm{MHz}$ (one carrier of GSM). Almost $85 \%$ of the market has been captured by all India operators and remaining $15 \%$ market is with other operators. The market share hold by $2 \mathrm{G}$ operators (GSM and CDMA) is given in Figure 3.

Similarly, the average spectrum assigned to pan India operators is more than $6.0 \mathrm{MHz}$ in $900 / 1800 \mathrm{MHz}$ band and other operators have been assigned between $4.4 \mathrm{MHz}$ to $5.0 \mathrm{MHz}$ in a TSA. An entire spectrum of telecom services have not been not assigned through market mechanisms. A detail of allocation of spectrum in different TSAs to various operators is given in Table 2. 
Spectrum Trading in India and 5G 165

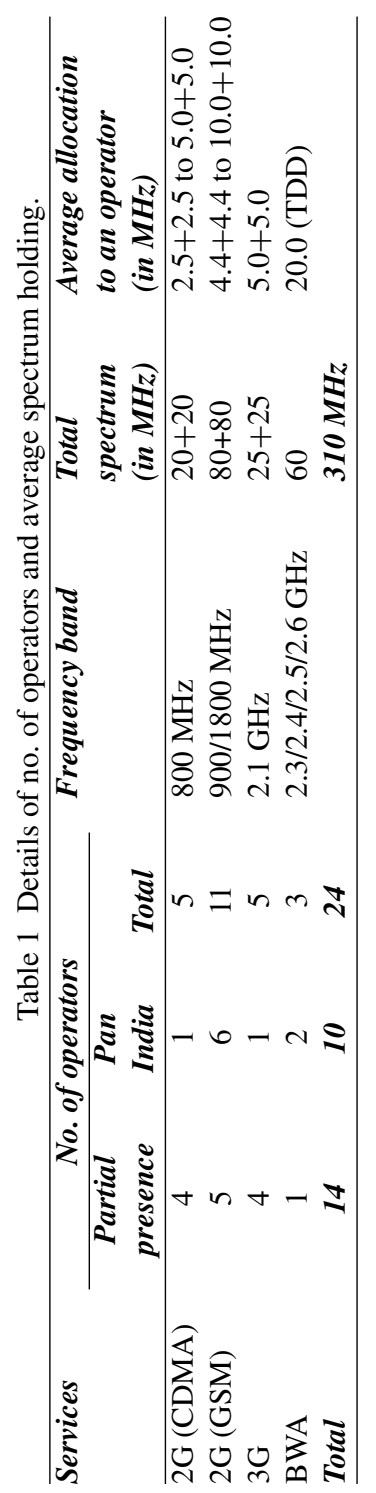




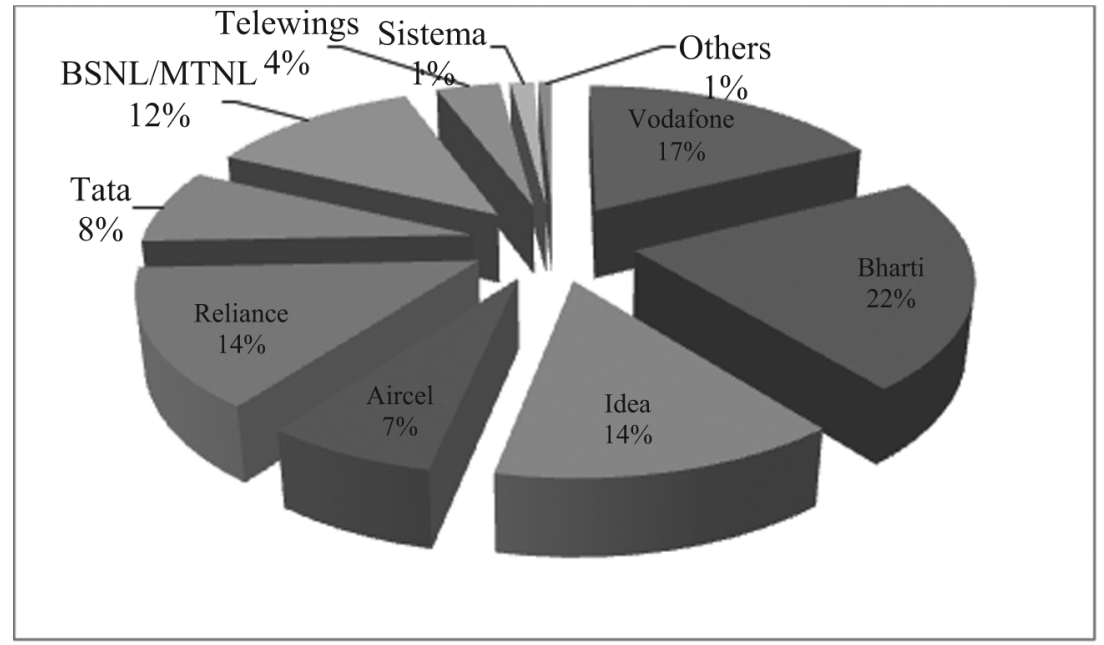

Figure 3 Marker share of $2 \mathrm{G}$ operators [9].

The spectrum for $3 \mathrm{G}$ and BWA services was auctioned in 2010. In 20122013 , two phases of the auction was conducted for spectrum in 800/900/1800 $\mathrm{MHz}$ band. Almost all assigned 2G spectrum in $800 / 900 / 1800 \mathrm{MHz}$ band (except small portion, which sold in 2012 auction in $1800 \& 800 \mathrm{MHz}$ band) is through either First Come First Served (FCFS) or Beauty Parade method. Spectrum assigned without auction is technology specific means that they can provide only GSM/CDMA services as applicable in the frequency band. Auctioned spectrum is liberalized and contiguous means that operators are free use any technology [10]. 2G GSM and CDMA services are available almost every part of India. However, no such wide coverage is available in case of $3 \mathrm{G}$ services. Roll out of $3 \mathrm{G}$ services is limited in urban areas only.

The LTE based 4G service has slowly entered into Indian market in 2.3$2.4 \mathrm{GHz}$ band (BWA-TDD mode). Recently, Bharti has launched $4 \mathrm{G}$ service in 4 cities namely Kolkata, Bengaluru, Pune \& Chandigarh and likely to be started in Delhi by September 2013 [12]. BSNL has launched WiMAX based $4 \mathrm{G}$ services in few cities of India. The remaining players are yet to launch their services. Due to limited coverage and additional capex at this frequency, rollout is limited to metros/urban sectors only. No further rollout is possible in other areas in next 2-3 years, even more time require for covering rural areas. However, if option be given to operators for upgradation of services in $900 / 1800 \mathrm{MHz}$ band, situation would have been entirely different. Faster rollout is possible due to wide coverage at $900 \mathrm{MHz}$ band. In most of the 
Table 2 Spectrum allocation in different TSAs to operators [9].

\begin{tabular}{lccccc}
\hline Service Area & $\mathbf{0 - 5 . 0}$ & $\mathbf{5 . 1 - 6 . 2}$ & $\mathbf{6 . 3 - 8 . 0}$ & $\mathbf{8 . 1 - 1 0}$ & Total \\
& $\mathbf{M H z}$ & $\mathbf{M H z}$ & $\mathbf{M H z}$ & $\mathbf{M H z}$ & \\
\hline Delhi & 2 & 0 & 1 & 3 & 6 \\
Mumbai & 4 & 0 & 0 & 4 & 8 \\
Kolkata & 3 & 1 & 1 & 2 & 7 \\
Maharashtra & 4 & 0 & 1 & 3 & 8 \\
Gujarat & 5 & 2 & 1 & 1 & 9 \\
Andhra Pradesh & 4 & 1 & 1 & 2 & 8 \\
Karnataka & 3 & 1 & 1 & 2 & 7 \\
Tamilnadu & 3 & 0 & 1 & 3 & 7 \\
Kerala & 3 & 1 & 2 & 1 & 7 \\
Punjab & 4 & 1 & 3 & 0 & 8 \\
Haryana & 4 & 2 & 0 & 2 & 8 \\
Utter Pradesh (West) & 5 & 1 & 1 & 2 & 9 \\
Utter Pradesh (East) & 5 & 1 & 1 & 2 & 9 \\
Rajasthan & 3 & 2 & 1 & 1 & 7 \\
Madhya Pradesh & 3 & 1 & 3 & 1 & 8 \\
West Bengal & 3 & 2 & 1 & 1 & 7 \\
Himachal Pradesh & 3 & 3 & 0 & 1 & 7 \\
Bihar & 4 & 1 & 2 & 2 & 9 \\
Orissa & 3 & 1 & 2 & 1 & 7 \\
Assam & 1 & 2 & 2 & 1 & 6 \\
North East & 2 & 2 & 1 & 1 & 6 \\
Jammu \& Kashmir & 3 & 1 & 2 & 0 & 6 \\
Total & $\mathbf{7 4}$ & $\mathbf{2 6}$ & $\mathbf{2 8}$ & $\mathbf{3 6}$ & $\mathbf{1 6 4}$ \\
\hline
\end{tabular}

countries, 4G services are being provided in 900/1800 MHz band. The same is not possible in India due to small and fragmented spectrum holdings in 800 , 900 and $1800 \mathrm{MHz}$, license issued for specific technology and uncertainties over the availability of additional spectrum.

The India's telecom sector growth is hampering due to excessive fragmentation of spectrum holdings. The spectrum HHI in India is about 0.15 (in a scale where 1 indicates monopoly occupancy of the spectrum) [8]. Presently, spectrum has been de-linked with the operating license. Any additional spectrum, if required by the operator, will have to buy from the market [13]. Merger $\&$ acquisition (between two or more than two companies) is one solution to get additional spectrum but the process is complicated involves coordination with 2-3 different government departments and take considerable time. They can buy additional spectrum through auction but auction can be conducted when free spectrum is available with regulator. Therefore, it is almost impossible for an operator to get additional spectrum in the changed regulatory 
environment. Spectrum trading could be an option by which an operator can acquire additional spectrum from other operators without going into much complexity.

\section{Possible Regulatory Provisions for spectrum trading in India}

Spectrum trading has not yet been permitted in India with a view that the market is unbalance, 3-4 operators have captured almost $80 \%$ of the market and spectrum assigned to these operators are at nominal price or free of cost (spectrum was bundled with a license) whereas other operators were obtained spectrum through market mechanism [9]. There is a risk of spectrum consolidation which will disturb the market dynamics. Presently, the situation has been changed. The Government de-linked the spectrum from license and announced that spectrum shall be made available at a price determined through market related processes in future. The Government committed in National Telecom Policy 2012 [13] for seamless delivery of converged services in a technology and service neutral environment and to liberalization of spectrum to enable use of spectrum in any band to provide any service in any technology as well as to permit spectrum pooling, sharing and later, trading to enable optimal utilization of spectrum through the appropriate regulatory framework. India could be a good market for spectrum trading due to the following reasons:

- Spectrum hold by any operator is not high in quantum and fragmented

- Number of operators in each service area are considerably high

- Spectrum available through market mechanism only

- Market dynamics is unbalanced; 3-4 operators capture almost $80 \%$ of the market

- No pan India operator in 3G services

- Roll out of $3 \mathrm{G}$ is not as good as $2 \mathrm{G}$ services

- 4G services launched in few cities only

- Tele-density is about at 79

Presently, spectrum holders cannot transfer/lease spectrum. They have two options, either use it or surrender it. No holders can claim spectrum as 'Property Right'. Trading is present form is not possible. Initially permission may be given to holder for transfer/lease of spectrum to materialize trading business. Trading parameters would be bandwidth, location and duration. Besides full transfer, partial transfer of all the three parameters may be allowed as demand in a telecom service area may not be uniform, it is high in the urban sector 
and low in the rural sector. In case of full transfer, the buyer will have to buy spectrum for the entire service area, which may not be viable from business point. Therefore, location wise (district level) in a TSA may be allowed for

trading. A minimum unit for all the three variables should be defined. Unit of location parameter would be district level in a service area, bandwidth may be in multiple of $1 \mathrm{MHz}$ or $0.5 \mathrm{MHz}$ and the unit of duration may be 1 years or its multiple.

\subsection{Frequency Band}

Market mechanism has so far been adopted for telecom bands only. In the current situation, trading is largely possible in telecom sector only. Auctioned band is the best candidates for spectrum trading. Other bands which fall in the IMT bands category like Public Mobile Radio Trunking System (PMRTS) band (in $800 \mathrm{MHz}$ ) may be opened for spectrum trading. Besides access spectrum, operators also need spectrum for backhaul, which assigned in $7 \mathrm{GHz}$, $14 \mathrm{GHz}, 21 \mathrm{GHz}$ and $28 \mathrm{GHz}$ bands. Spectrum in these bands for backhaul services is limited and allotted through FCFS method on administrative pricing basis [3]. Almost 9-10 operators are present in each service area. Backhaul spectrum is very much in demand. It is not possible to fulfill the requirement of operators due to scarcity. These backhaul bands may also be put for trading to mitigate the shortage.

The initial candidate bands for spectrum trading will be: PMRTS band ( 800 MHz), CDMA band (800 MHz), GSM band (900 MHz), GSM Band (1800 $\mathrm{MHz}), 3 \mathrm{G}$ Band $(2.1 \mathrm{GHz}), \mathrm{BWA}(2.3-2.4 \mathrm{GHz} \& 2.5-2.6 \mathrm{GHz}), \mathrm{BWA}$ band (3.3-3.4 GHz \& 3.4-3.6 GHz) and Backhaul bands $(7.0 \mathrm{GHz}, 14.0 \mathrm{GHz}, 21.0$ $\mathrm{GHz}$ and $28.0 \mathrm{GHz}$ ). The spectrum hold by defence, police and other security agencies, public disaster authority and other Government agencies may not be allowed for trading due to security reasons.

\subsection{Liberalization of Spectrum}

Liberalization is required for efficient usage otherwise objective will be forfeited. Only liberalized spectrum should be allowed for spectrum trading. Auctioned spectrum has already been liberalized while administrative allocated bands are un-liberalized. The Government has made provision that un-liberalized spectrum in 800/900/1800 $\mathrm{MHz}$ band can be converted into liberalized by paying one time spectrum charges. However, in other 
proposed bands, price mechanism may be devised for conversion into liberalized spectrum.

\subsection{Roll Out Obligations}

As per present spectrum policy, assigned is associated with certain obligations on the part of the license like roll out obligations. There are pre-defined penalties for delay, if roll out obligations are not completed in specified time limit. Regarding licensing obligations, it would be appropriate that trading will be allowed after completion of obligations associated with the license. After transaction of trading, obligations will be lying with buyers for the sold portion of spectrum and obligations corresponding to unsold spectrum will still lying with the seller. A heavy penalty may be imposed on seller in case of non-completion of obligations. This would give a balanced approach towards obligations.

To maintain the market dynamics, a spectrum cap in each band and across all the bands may also be imposed otherwise consolidation may disturb the market harmony. Presently, Spectrum cap has already been imposed while auction of $2 \mathrm{G}$ spectrum in 2012 which states the spectrum cap with a band and across all the bands is $50 \%$ and $25 \%$ of total assigned spectrum respectively. The same may be retained as spectrum hold by an operator is not very high [10]. Besides spectrum cap, a relatively higher annual spectrum usage charges may also be imposed to discourage spectrum hording.

\section{Spectrum requirement for $5 \mathrm{G}$}

Today's cellular operation is limited between $700 \mathrm{MHz}$ and $2.6 \mathrm{GHz}$. The global spectrum allocation for all cellular technologies does not exceed 780 $\mathrm{MHz}$ and that too in different bands [14]. Each band has their own propagation characteristics, which forced the industry to design radio equipment to accommodate all the bands and technologies. As per Report ITU-R M.2078 [15]: 'Estimated spectrum bandwidth requirements for the future development of IMT-2000 and IMT-Advanced', the predicted spectrum requirements by 2020 would be between 1280 to $1720 \mathrm{MHz}$. This bandwidth has been envisaged considering demand arises through $4 \mathrm{G}$ communication. The next future generation would be $5^{\text {th }}$ generation. In [16], the concept of future $5^{\text {th }}$ generation mobile communication has been given as:

$4 \mathrm{G} \& \mathrm{WISDOM} \Rightarrow 5 \mathrm{G}$ 


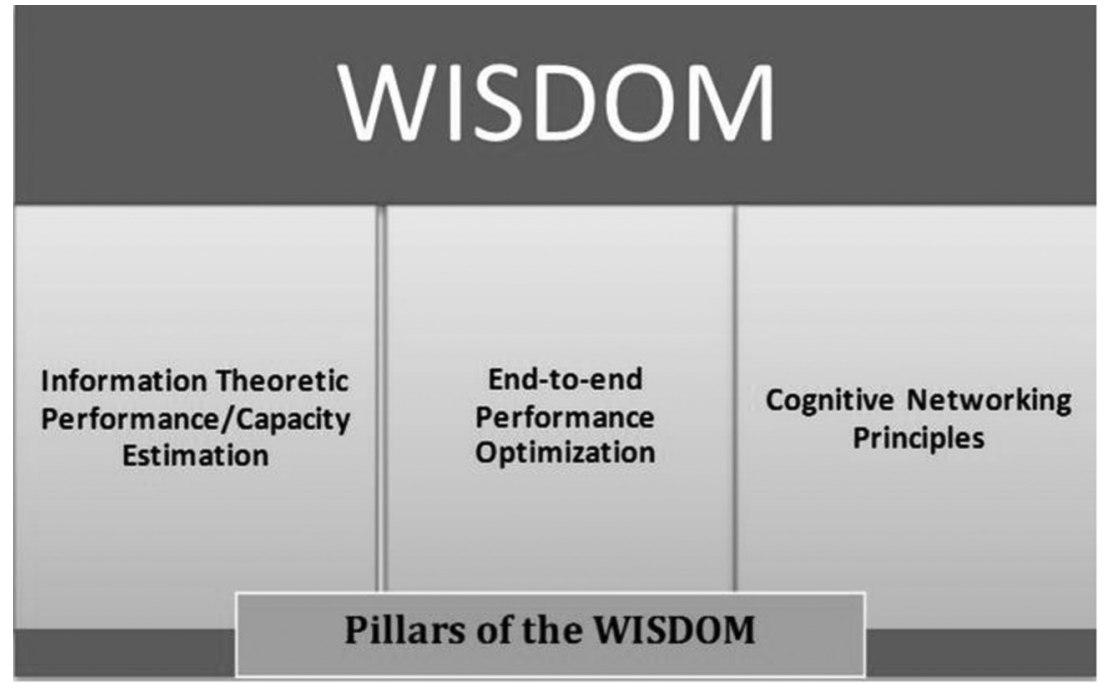

Figure 4 Concept of WISDOM.

The WISDOM, as shown in Figure 4, principle brings unlimited wireless world interconnection, convergence, and cooperation (geographically including cities, countries, continents, and finally, the whole world), together with a large variety of multimedia services at very high data rates, and becomes the main $5 \mathrm{G}$ definition point.

Gilder's Law [17] predicts a sixfold increase of the available Bit Rate every 1.5 years it will take approx. six years to achieve the 1 Tbps. Therefore, $5 \mathrm{G}$ envisage data speed of $1 \mathrm{Tbps}$. The spectrum bands do not have the capability to hold such enormous data. We would have to look at millimetre wave. Recent studies suggest that mm-wave frequencies could be used for wireless communication and it could be augmented the currently saturated $700 \mathrm{MHz}$ to $2.6 \mathrm{GHz}$ bands for wireless communications [14]. Mm-wave spectrum would allow significantly expanding the channel bandwidths and could carry huge data successfully. The future system would lead to a new type of architecture in which connectivity between base stations to user would be provided through millimeter waves. As per NFAP 2011 [3], millimeters wave has been allocated largely for earth exploration satellite and space research. Fixed and Mobile services have also been present as primary services. Spectrum is largely available for research. Therefore, we hope that the vision of $5 \mathrm{G}$ could be realized in the near future, which would make a wonderful difference in the peoples' lives. Spectrum trading at millimeter waves may not be applicable at 
this stage but in future trading may require when congestion would increase. However, a coordination/co-existence study would be required with existing users because services presently working in this range need protection from high power mobile communication.

\section{Conclusions}

The $2 \mathrm{G}$ and $3 \mathrm{G}$ mobile services are running successfully in India. $4 \mathrm{G}$ services is limited to few metro cities only, and further expansion of $4 \mathrm{G}$ services seems to be taking a longer time due to non-availability of spectrum in the lower bands. As discussed in the chapter, highly fragmented spectrum holdings, high number of operators and high level of activity offers a conducive environment for spectrum trading in Indian telecom sector. Spectrum trading may not be much successful in other countries. If implemented in India, it would improve technical as well as economic efficiency of spectrum.

\section{References}

[1] Rysavy research. Mobile broadband Explosion. www.4gamericas.org/documents/ 4G\%20Americas \%20Mobile\%20Broadband\%20Explosion \%20August\%2020121.pdf

[2] Recommendations on Spectrum Management and Licensing Framework (2010). www. trai.gov.in

[3] National Frequency Allocation Plan (NFAP) 2011 of India. www.wpc.dot.gov.in

[4] Martin Cave, Chris Doyle and William Webb. Essentials of Modern Radio Spectrum Management.Cambridge University Press (2007).

[5] Carlos E. Caicedo, Martin Weiss. Characterization and Modelling of Spectrum Trading markets. http://www.academia.edu/571899/ Characterization_and_Model ing_of_Spectrum_Trading_Markets

[6] Consultation paper on Overall Spectrum Management and review of license terms and conditions(2009).www.trai.gov.in

[7] European practices in trading of spectrum usage rights. www.cept.org/.../European\% 20practices\%20in\%20trading\%20of\%20S

[8] V. Sridhar, Rohit Prasad. Nothing wrong with spectrum sharing. http://www.thehindu businessline.com/opinion/nothing-wrong-with-spectrum-sharing/article4992619.ece

[9] The Indian Telecom Services Performance Indicators March 2013. www.trai.gov.in

[10] Auction of Spectrum. www.dot.gov.in

[11] Spectrum allocation to $2 \mathrm{G}, 3 \mathrm{G} \& \mathrm{BWA}$ services. www.wpc.dot.gov.in

[12] http://www.airtel.in/forme/wireless-internet/4g_lte/4g_lte_coverage/4g_coverage

[13] National Telecom Policy 2012 of India. www.dot.gov.in

[14] Rappaport T.S et.al. Millimeter Wave Mobile Communications for 5G Cellular: It will work. Open Access, IEEE.(2013). DOI: 10.1109/ACCESS.2013.2260813 
[15] ITU-R M.2078 Report. http://www.itu.int/dms_pub/itu-r/opb/rep/R-REP-M.2078-2006PDF-E.pdf

[16] Prasad R. Introducing 5G Standardisation. 11thGISFI StandardisationSeries Meeting. www.gisfi.org

[17] Glider's Law. http://en.wikipedia.org/wiki/George_Gilder

\section{Biographies}

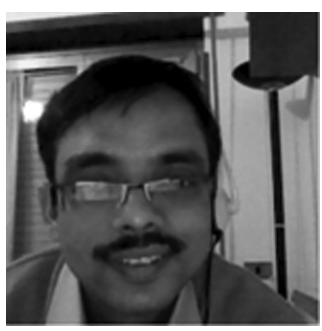

Purnendu S M Tripathi an Indian Radio Regulatory Services (IRRS) officer of 1998 batch. He is having technical experience of 12 years in the field of Radio Communications/Radio Spectrum Management. He is Engineer in Wireless Planning \& Coordination Wing of Department of Telecommunications (DOT), Ministry of Communications \& IT, Government of India. In DOT, he is associated with spectrum management activities, including in spectrum planning and engineering and policy regarding regulatory affairs for new technologies and related research \& development activities and ITU-R related matter. He was also associated with implementation of a very prestigious World Bank Project on National Radio Spectrum Management and Monitoring System (NRSMMS). His area of interest includes Radio Regulatory affairs for new technologies and cognitive radio. He has also worked as research fellow in Department of Electronics, University of Tor Vergata, Rome, Italy. Presently, he is doing Ph.D. from Aalborg University, Denmark under Prof.Ramjee Prasad.

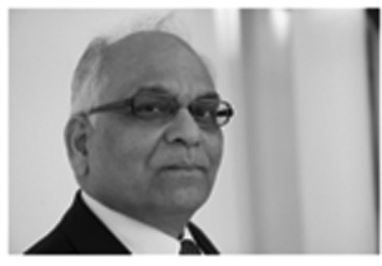

Ramjee Prasad Ramjee Prasad is currently the Director of the Center for TeleInfrastruktur (CTIF) at Aalborg University, Denmark and Professor, Wireless Information Multimedia Communication Chair.

Ramjee Prasad is the Founding Chairman of the Global ICT Standardization Forum for India (GISFI: www.gisfi.org) established in 2009. GISFI has the purpose of increasing of the collaboration between European, Indian, Japanese, North-American and other worldwide standardization activities in the area of Information and Communication Technology (ICT) and related application areas. He was the 
Founding Chairman of the HERMES Partnership - a network of leading independent European research centres established in 1997, of which he is now the Honorary Chair.

He is the founding editor-in-chief of the Springer International Journal on Wireless Personal Communications. He is a member of the editorial board of other renowned international journals including those of River Publishers. Ramjee Prasad is a member of the Steering, Advisory, and Technical Program committees of many renowned annual international conferences including Wireless Personal Multimedia Communications Symposium (WPMC) and Wireless VITAE. He is a Fellow of the Institute of Electrical and Electronic Engineers (IEEE), USA, the Institution of Electronics and Telecommunications Engineers (IETE), India, the Institution of Engineering and Technology (IET), UK, and a member of the Netherlands Electronics and Radio Society (NERG), and the Danish Engineering Society (IDA). He is a Knight ("Ridder") of the Order of Dannebrog (2010), a distinguished award by the Queen of Denmark. 